\title{
ELENA G. DE WHITE Y EL LIBRO DE APOCALIPSIS
}

\author{
Jon Paulien ${ }^{1}$
}

\section{Resumen}

Para los adventistas del séptimo día, raramente se estudia el libro de Apocalipsis sin hacer referencia a los escritos de Elena G. de White, una muy respetada co-fundadora de la Iglesia Adventista del Séptimo Día e importante escritora en el siglo XIX. Por esta razón, en una breve serie de párrafos, el presente ensayo aborda los escritos de Elena G. de White en relación al libro de Apocalipsis.

Palabras clave: Elena G. de White, Apocalipsis, Adventistas del séptimo día

${ }^{1}$ Doctor en Teología por la Universidad Andrews, Estados Unidos. Director de la Escuela de Religión de la Universidad Loma Linda, Estados Unidos. Email: jpaulien@llu.edu 


\title{
ELLEN G. WHITE AND THE BOOK OF REVELATION
}

\begin{abstract}
For Seventh-day Adventists the study of the book of Revelation rarely occurs without reference to the writings of Ellen G. White, a highly-respected founder of the Adventist Church and a major female author of the 19th Century. For this reason, the present essay addresses her writings on Revelation (which are fewer than most people who know of her realize).
\end{abstract}

Keywords: Ellen G. White, Book of Revelation, Seventh-day Adventists 


\section{Introducción}

Para los adventistas del séptimo día, el estudio del libro de Apocalipsis raramente se hace sin hace referencia a los escritos de Elena G. de White, quien es considerada por el adventismo como la mensajera del Señor, co-fundadora de la Iglesia Adventista del Séptimo Día y, además, una importante escritora en el siglo XIX. ${ }^{1}$ A pesar que sus comentarios sobre el Apocalipsis parecen estar basados en la erudición de su tiempo, aun así, es posible notar la profundidad de su análisis gracias al fruto de su estudio personal y de la revelación divina. Es por ello que sus escritos continúan teniendo un poder espiritual transformador que impactan a las personas de hoy de la misma manera como lo hicieron en su tiempo. En una breve serie de párrafos, me gustaría abordar sus escritos en relación al libro de Apocalipsis — que en realidad son menos de los que muchos creen. ${ }^{2}$

\section{Elena G. de White y el Apocalipsis}

La opinión de Elena G. de White sobre el libro de Apocalipsis puede percibirse claramente en los dos principales lugares donde directamente resume su comprensión del contexto y propósito del libro. El primer pasaje, y el más exhaustivo, fue publicado en la Review and Herald del 18 de febrero de 1890 y republicado en Testimonios para los Ministros. ${ }^{3}$ El segundo pasaje consiste en dos capítulos en Hechos de los Apóstoles. ${ }^{4}$

${ }^{1}$ Un excelente estudio sobre la vida y obra de Elena G. de White puede ser encontrado en Jerry Moon y Denis Kaiser, "For Jesus and Scripture: The Life of Ellen G. White", en The Ellen G. White Encyclopedia, eds. Denis Fortin y Jerry Moon (Hagerstown, MD: Review and Herald, 2013), 18-95; en adelante EGWEnc.

${ }^{2}$ El contenido de estos párrafos está basado mayormente en mi estudio publicado como: "Revelation, Book of", EGWEnc, 1085-1087.

${ }^{3}$ Testimonio para los ministros (Buenos Aires: Asociación Casa Editora Sudamericana, 1979), 112-119. En adelante TM.

${ }^{4}$ Hechos de los Apóstoles (Nampa, ID: Pacific Press, 1967), 454-473. 


\section{Convicción básica}

El enfoque de Elena G. de White hacia el Apocalipsis está basado en una convicción básica. Ella creía que una "explosión" en el tiempo del fin, haciendo eco a los eventos de Daniel y Apocalipsis, fue un factor clave detrás del ascenso del movimiento adventista. En otras palabras, ella sintió que en su tiempo Dios había levantado un velo que tapaba estos libros, permitiendo que puedan ser comprendidos plenamente. ${ }^{5}$ El libro del Apocalipsis, por lo tanto, estaba dirigido para aquellos que vivían en los últimos días y donde el tiempo del cumplimiento profético se hallaba cerca. ${ }^{6}$

\section{La necesidad de más estudio}

Aunque los pioneros adventistas habían invertido mucho tiempo estudiando el Apocalipsis, Elena G. de White estaba convencida de que el libro aún no había sido comprendido plenamente. ${ }^{7}$ Quienes deseaban una comprensión más profunda, necesitarían aproximarse al libro "con humildad y mansedumbre”. ${ }^{8}$ La comprensión más profunda del Apocalipsis que ellos ganarían sería una gran bendición para el desarrollo del carácter. ${ }^{9} \mathrm{Ha}-$ bría un "gran reavivamiento" ${ }^{10}$ caracterizado por "una experiencia religiosa completamente nueva". ${ }^{11}$ Así que le objetivo principal del Apocalipsis, según su forma de pensar, no era el conocimiento, sino el carácter.

En términos de método, este estudio tendrá que desarrollarse

${ }^{5} T M 113$.

${ }^{6}$ TM 113, 115, 116; Testimonio para la iglesia (Doral, FL: Asociación Publicadora Interamericana, 2004), 6:67-69.

${ }^{7}$ TM 113.

${ }^{8}$ Ibíd., 114.

${ }^{9}$ Ibíd.

${ }^{10}$ Ibíd., 113.

${ }^{11}$ Ibíd., 114. 
en dos formas que, de alguna manera, son contrastantes. Por un lado, Elena G. de White defendía el estudio del Apocalipsis en el contexto de Daniel, como una continuación de las visiones que se dan allí. ${ }^{12}$ Los dos libros debían ser considerados como compañeros cercanos. ${ }^{13}$ Por otro lado, ella instó a estudiar el Apocalipsis en el contexto de todas las demás profecías de la Biblia. ${ }^{14}$ Ella incluso llegó al extremo de sugerir que en el libro del Apocalipsis "todos los libros de la Biblia se encuentran y terminan". ${ }^{15}$ De esta manera, un enfoque integral de la Biblia con un énfasis especial en Daniel era el método básico que ella buscaba aplicar al Apocalipsis. Pero, aunque Daniel y Apocalipsis son complementarios, los dos libros no son iguales. Mucho de lo que Daniel contiene fue sellado (Dn 12:4), pero el Apocalipsis no fue sellado, sus misterios siempre han estado "abiertos para que todos los estudien". ${ }^{16}$

\section{Propósito del libro}

Elena G. de White expresó un elevado propósito espiritual para el libro del Apocalipsis. (1) El libro fue diseñado para que los agentes humanos miren detenidamente a Dios y exalten su santa ley. ${ }^{17}$ Cuando los lectores vieran la gloria de Dios descrita allí, el orgullo humano estaría por el suelo. (2) La profunda conexión entre el cielo y la tierra, en las visiones apocalípticas, estaba diseñada para enseñar que la conexión entre Dios y su pueblo es "cercana y firme". ${ }^{18}$ (3) Correctamente entendido, el Apocalipsis

${ }^{12}$ TM 114; Primero escritos (Nampa, ID: Pacific Press, 1962), 231; en adelante PE.

${ }^{13} T M 115 ; H A p 467$.

${ }^{14} T M 112$.

${ }^{15} \mathrm{HAp} 476$.

${ }^{16}$ HAp 466; cf. Review and Herald, 31 de agosto de 1897.

${ }^{17} T M 112$.

${ }^{18}$ TM 114, HAp 468. 
permite a los lectores "elevar a Jesús como el centro de toda esperanza" ${ }^{19} \mathrm{El}$ Apocalipsis no fue diseñado para satisfacer la curiosidad acerca del futuro, sino para fijar los ojos humanos en Jesús y alentarlos a caminar con Dios.

\section{Autoría y fecha}

El punto de vista de Elena G. de White acerca de la autoría y la fecha de composición del Apocalipsis estaba en armonía con las tradiciones de los Padres de la iglesia, así como el del consenso conservador alrededor de fines del siglo veinte. Ella enseñó que el escritor del Apocalipsis fue el último de los discípulos; a saber, Juan, el hijo del Zebedeo. ${ }^{20}$ El Apocalipsis fue escrito en el tiempo del emperador Domiciano, quien convocó a Juan a Roma para ser juzgado por su fe, lo arrojó dentro de una caldera de aceite hirviendo, y luego lo desterró a la isla de Patmos, un lugar comúnmente conocido para el destierro de criminales. ${ }^{21}$

\section{4}

\section{Enfoque de interpretación}

Donde sus declaraciones son claras, Elena G. de White parece aplicar consistentemente el método "historicista" al texto del Apocalipsis. "22 "Algunas de las escenas descritas en esa profecía pertenecen al pasado, otras se están cumpliendo ahora; algunas tienen que ver con el fin del gran conflicto entre los poderes de las tinieblas y el Príncipe del cielo, y otras revelan los triunfos y alegrías de los redimidos en la tierra nueva”. ${ }^{23}$ Aquí es posible señalar dos ejemplos de su enfoque historicista: (1) Ella ve la carta

\footnotetext{
${ }^{19} T M 118$.

${ }^{20} \mathrm{HAp} 454$.

${ }^{21} \mathrm{HAp}$ 455-456.

${ }^{22} P E 230$.

${ }^{23} \mathrm{HAp} 466$.
} 
a la iglesia de Éfeso (Apo 2:1-7) como una descripción de toda la iglesia cristiana en la era apostólica (siglo I d.C. ${ }^{24}$ y (2) el mensaje a Laodicea es particularmente aplicable al pueblo adventista en el tiempo del fin. ${ }^{25}$

Al mismo tiempo, sin embargo, también reconoció que el libro de Apocalipsis fue dado "para la orientación y el aliento de la iglesia durante la dispensación cristiana", ${ }^{26}$ algo más emparentado al enfoque "idealista". Las promesas vencedoras de las siete cartas, por ejemplo (incluyendo Apo 2:7; $3: 5$ y 3:21), pertenecen a todos los fieles que lucharon contra el mal a lo largo de los siglos de oscuridad y superstición. ${ }^{27}$ El mensaje a Éfeso ofrece un ejemplo de cómo reprender los pecados para los ministros de la actualidad. ${ }^{28}$ El mensaje a Laodicea aplica a todos los que profesan mantener la ley de Dios pero que no son hacedores de ella. ${ }^{29}$

Pero, sin importar la manera en que se estudie el Apocalipsis, Elena G. de White ve al libro de Apocalipsis cumpliendo un rol especial en la era final de la historia de la tierra. ${ }^{30}$ Las verdades del libro se "dirigen a los que viven en estos últimos días". ${ }^{31}$ Muchas partes del Apocalipsis (en este contexto ella cita Apo 15:2-3; 21:2-22; 22:1-5, 14; y 14:2-5) están interesadas directamente con el triunfo supremo de la iglesia remanente de Dios. ${ }^{32}$ Ella creía que su generación se estaba

${ }^{24} H A p, 462,467$.

${ }^{25}$ Manuscrito 33, 1894; citado en Seventh-day Adventist Bible Commentary: Philippians to Revelation(Hagerstown, MD: Review and Herald, 1957), 7:961, en adelante 7BC.

${ }^{26} \mathrm{HAp} 466$.

${ }^{27}$ Ibíd., 469-470.

${ }^{28}$ Manuscrito 136, 1902, citado en 7BC 959.

${ }^{29}$ Review and Herald, 17 de octubre de 1899; El Deseado de todas las gentes (Nampa, ID: Pacific Press, 1955), 453-454; en adelante DTG.

${ }^{30} T M$ 113, 115, 116; El conflicto de los siglos (Doral, FL: Asociación Publicadora Interamericana, 2007), 340-341; en adelante CS.

${ }^{31} T M 113$.

${ }^{31} \mathrm{HAp}$ 471-473. 
acercando al tiempo en que estas profecías serían cumplidas. ${ }^{33}$ Así que mientras el historicismo era su enfoque principal para el Apocalipsis, también comprendía que todo el libro tendría una importancia especial para los últimos días. ${ }^{34}$ Incluso las cadenas de la historia representadas allí, ayudarían al pueblo de Dios a estimar correctamente el valor de las cosas y discernir "el verdadero objetivo de la vida". ${ }^{35}$

\section{Resumen de sus interpretaciones}

Lo que resta de este ensayo resume algunos puntos aleatorios de interpretación que pueden ser encontrados esparcidos a lo largo de los escritos de Elena G. de White, especialmente en el libro El Conflicto de los Siglos. Los siguientes conceptos serán tratados en el orden de los textos en el Apocalipsis a los cuales aplican, comenzando con el capítulo 1 y finalizando con el capítulo 22. Elena G. de White entendía que el "Día del Señor", cuando el espíritu vino sobre Juan (Apo 1:9-10), era el día sábado. ${ }^{36}$ Ella asocia la escena celestial de Apocalipsis 4-5 con el ascenso de Cristo al cielo después de su resurrección. ${ }^{37}$ Tanto el león como el cordero (Apo 5:5-6) son símbolos de Cristo, representando la unión del poder omnipotente con el amor abnegado. ${ }^{38}$ Las señales celestiales del sexto sello (Apo 6:12-14), usualmente son asociadas con eventos que llevaron al movimiento adventista al siglo XIX. ${ }^{39}$

Aunque su lenguaje no llega a ser una confirmación, Elena G. de White habla con aprobación de las predicciones de Josiah Litch acerca

${ }^{33} T M 113$.

${ }^{34} T M 116$.

${ }^{35}$ Profetas y Reyes (Nampa, ID: Pacific Press, 1957), 403.

${ }^{36}$ HAp 464.

${ }^{37} D T G 773-774$.

${ }^{38} \mathrm{HAp} 470$.

${ }^{39}$ CS 333-334. 
de la quinta y sexta trompeta. ${ }^{40}$ La escena de Apocalipsis 10 describe un punto en la historia cuando los períodos de tiempo de Daniel han llegado a su conclusión y la proclamación final del evangelio ha comenzado. ${ }^{41}$ Los dos testigos de Apocalipsis 11 representan al Antiguo y Nuevo Testamentos, y las descripciones de dichos capítulos representan cómo la Biblia fue tratada en el curso de la Revolución Francesa. ${ }^{42}$

Elena G. de White describió la guerra en el cielo de Apocalipsis 12:7-12 en dos formas diferentes, pero complementarias. Por un lado, la escena describe una amenaza al gobierno del cielo que ocurrió incluso antes de la creación del mundo. Satanás, y todos los ángeles que los siguieron, fueron físicamente expulsados del cielo en esa ocasión. ${ }^{43}$ Por otro lado, la expulsión del dragón refleja el impacto que tuvo la cruz sobre los afectos del universo. ${ }^{44}$ En la cruz, Satanás perdió cualquier credibilidad espiritual que pudo haber retenido en los lugares celestiales. ${ }^{45}$

Interpretaba a la bestia marítima de Apocalipsis 13:1-10 como representando al papado de la Edad Media, ${ }^{46}$ el cual tendrán un rol en el tiempo de fin en oposición al verdadero pueblo de Dios. ${ }^{47}$ Aunque muchas de sus declaraciones contra el liderazgo de la Iglesia Católica Romana son dolorosamente fuertes de acuerdo a los estándares actuales, ${ }^{48}$ otras declaraciones nos advierten en contra de personalizar la oposición

${ }^{40}$ CS 334-335.

${ }^{41}$ Manuscrito 59, 1900; citado en 7BC 971.

${ }^{42}$ CS 265-288.

${ }^{43}$ Review and Herald, 28 de enero de 1909; Carta 114, 1903; citado en 7BC 973.

${ }^{44}$ Manuscrito 50, 1900; citado en 7BC 974.

${ }^{45}$ The Spirit of Prophecy (Battle Creek, MI: Seventh-day Adventist Publishing Association., 1878), 3:194-195.

${ }^{46}$ CS 49-60.

${ }^{47}$ CS $445-450$.

${ }^{48}$ CS 563-581. 
al papado. ${ }^{49}$ Ella también reconoce que el tiempo y el lugar deben ser considerados cuando se expresa dicha oposición. ${ }^{50}$

Asimismo, ella entendió que la bestia de la tierra de Apocalipsis 13:11-14 es los Estados Unidos de Norteamérica en su colaboración escatológica con la jerarquía romana. ${ }^{51}$ La marca de la bestia es recibida cuando una persona rechaza el llamado final de Dios a la verdadera observancia del sábado y, al mismo tiempo, se someta a la imposición de la adoración del domingo en el tiempo del fin. ${ }^{52}$ Los tres ángeles de Apocalipsis 14:6-12 representan a los creyentes en el mensaje final de Dios que esparcen el último mensaje evangélico a lo largo y ancho del mundo. ${ }^{53}$

Elena G. de White no consideraba que la batalla del Armagedón (Apo 16:16) fuera un asunto militar en el Medio Este, o en algún otro lugar; para ella el Armagedón sería un conflicto espiritual en el día final entre el pueblo de Dios y las fuerzas del mal. ${ }^{54}$ Durante ese último conflicto, los principios espirituales fundamentales serán aclarados y las personas serán llevadas a tomar una decisión para sí mismos. Será un tiempo en el que la fe será probada, y no el poder o la capacidad física. ${ }^{55}$

Respecto a Apocalipsis 20, Elena G. de White era premilenialista. Creía que el milenio sería un período de mil años después de la segunda venida de Cristo. Durante ese período, la tierra estaría vacía de seres humanos, aunque Satanás y sus ángeles estarían confinados allí. El pueblo de Dios sería llevado al cielo en la segunda venida para pasar mil años con Dios. ${ }^{56}$

${ }^{49}$ El Evangelismo (Doral, FL: Asociación Publicadora Interamericana, 1994), 420; en adelante $E v$.

${ }^{50} T M 112 ; E v$ 417-420.

${ }^{51}$ CS 439-445.

${ }^{52}$ CS $445-450$.

${ }^{53}$ CS 311-312.

${ }^{54}$ Ver los comentarios en 7BC 982-983.

${ }^{55}$ Manuscrito 1a, 1890; citado en 7BC 983.

${ }^{56}$ CS 653-661. 
Al final del milenio, los impíos de todos los tiempos serán resucitados y el pueblo de Dios regresará a la tierra con la Nueva Jerusalén para presenciar la destrucción final del pecado, los pecadores y Satanás. ${ }^{57}$ La tierra luego será destruida por el fuego y Dios creará un nuevo cielo y una nueva tierra en la cual el pueblo fiel de Dios morará para siempre en alegría y perfecta armonía. ${ }^{58}$ Según la opinión de Elena G. de White, sin embargo, la mejor definición del cielo no son las riquezas o la gloria, sino la presencia de Cristo. ${ }^{59}$

\section{Conclusión}

En síntesis, es posible afirmar que el Apocalipsis es la continuación del libro de Daniel y la gran conclusión de la profecía bíblica en general. La autora se muestra conservadora respecto al autor y la fecha de composición del libro; y aunque se afilia al historicismo como perspectiva interpretativa, también consideró posible extraer aplicaciones espirituales mediante la lectura de este libro.

Finalmente, Elena G. de White entendió que las profecías del

Apocalipsis son la descripción histórica y escatológica de la lucha entre Dios, el Cordero, su Santuario y la verdadera adoración contra el Dragón, sus estratagemas y la falsa adoración impuesta por él; donde el Cordero y sus fieles salen claramente victoriosos. Es así que, estudiar el Apocalipsis desde la perspectiva desarrollada por Elena G. de White, provee al lector contemporáneo más que información, conlleva un sentido de vida profundamente coherente de cara al plan de redención y su gran Artífice, el Cordero y León de Judá, Jesucristo.

Recibido: $10 / 11 / 2015$

Aceptado: 05/01/2016

${ }^{57}$ CS 662-673.

${ }^{58}$ CS 673-678.

${ }^{59}$ Manuscrito 184, 1897; citado en 7BC 989. 